\title{
Study on Fault Analysis and early warning system of wind- induced disasters on transmission lines
}

\author{
LIN Fanqin ${ }^{1}$, JIA Ran $^{2}$, Yang Jingjing ${ }^{1}$, CAO Huaming ${ }^{1}$, LIU Hui ${ }^{2}$, DONG Pengtao ${ }^{1}$ \\ ${ }^{1}$ Weifang Power Supply Company, ShanDong, China \\ ${ }^{2}$ State Grid ShanDong Electric Power Research Institute, ShanDong, China
}

\begin{abstract}
Wind-induced disaster has become one of the most important disasters affecting the safe operation of power grid. In order to improve the effect of prevention and treatment of wind-induced disasters, it is very important to give early warning and real-time warning. Therefore, based on the climate characteristics of Shandong power grid, this paper presents the wind speed statistical law and the distribution characteristics of the number of days with strong wind. By analysing the mechanism of windinduced disasters and combining the fault data of five years, the characteristics and rules of wind deviation and foreign short-circuit fault are obtained. On this basis, an early warning model of wind deviation based on the calibration of minimum air gap and the determination of maximum wind speed is established. At the same time, there is a short circuit model based on visual image information. Based on GeoServer platform, we will develop an early warning system for wind-induced disasters of transmission lines, which can provide real-time warning and early warning for wind-induced disasters. The application of the system can reduce the impact of wind damage on the transmission line, and effectively improve the operation reliability of the line.
\end{abstract}

\section{Introduction}

As the climatic environment becomes severe and extreme weather increases, the transmission lines erected in the open air are extremely susceptible to severe weather, causing the probability of line failures to increase. At present, among all the natural disasters that affect the safe and stable operation of transmission lines, wind disasters have a wide range of impacts and great harm, and are the first of all types of disasters. Shandong is located in the eastern coastal zone, with frequent typhoons and complex micro-topography and microclimate environment. In recent years, there have been many severe convective weather in local areas, especially in Liaocheng, Dezhou, Jinan, Binzhou and other areas, west-to-east downburst and tornado disasters have occurred many times, which are extremely destructive ${ }^{[1,2]}$. The strong wind caused by severe convective weather sometimes exceeds the design wind speed of the line, and the transmission line fault caused by the wind disaster brings huge losses to the power system.

At present, Shandong Power Network faces a high risk of wind-induced fault, and it is very important and urgent to improve the wind resistance of transmission lines. The wind prevention work of transmission lines needs to be carried out from many aspects. The existing wind prevention system mainly relies on manual patrol and lacks online monitoring and automatic early warning systems.In order to better analyze the impact of wind on the failure of transmission lines based on the current situation of Shandong Power Network, this paper analyzes the impact mechanism of wind-induced disasters in combination with regional climate characteristics. At the same time from conducting statistical analysis of wind-induced disaster fault data in the past five years, combining with online micrometeorological monitoring and visualization image information, this paper establishes wind deviation and foreign body short-circuit models, realizing real-time monitoring of multi-channel environmental wind disasters and early warning of hidden defects, reducing the impact of wind damage on transmission lines and effectively improving the reliability of line operation.

\section{Climate characteristics}

Shandong is located in the East Asian monsoon region and the coastal zone. The average annual wind speed is $1.7 \sim 7.1 \mathrm{~m} / \mathrm{s}$. The areas with the highest wind speeds are in the coastal areas of the eastern part of the peninsula and Qingdao. The annual average wind speeds are mostly $4.0 \sim 5.0 \mathrm{~m} / \mathrm{s}$. The maximum wind speed in coastal areas is relatively high, most of which are $23 \sim$ $35 \mathrm{~m} / \mathrm{s}$, inland areas are generally between $16.0 \sim$ $27.0 \mathrm{~m} / \mathrm{s}$, the maximum wind speed of Mount Tai can reach $37.7 \mathrm{~m} / \mathrm{s}$, and the wind is above level $12^{[2]}$. The maximum wind speed is mainly concentrated in spring and summer, April is the most (26\% of the total number

\footnotetext{
* Corresponding author: 495889677@qq.com
} 
of windy days in the year), followed by June (23\%). Autumn and winter are the least in each month, the monthly percentage is only $2 \sim 3 \%$.

The distribution of annual strong wind days in Shandong is that the number of strong wind days in coastal areas is significantly more than inland, the eastern coast of the peninsula has the most, and the mountainous area in central Shandong has the least ${ }^{[3]}$.Most of the east coast of the peninsula is between 60 and 80 days, the peninsula inland and northern Shandong are mostly 20 to 40 days; the mountainous area in central Shandong is the least, generally less than 10 days; in other areas, it is mostly between 10 and 20 days .

\section{Wind-induced fault analysis}

\subsection{Fault mechanism analysis}

The winds that cause harm to transmission lines mainly include typhoons, downburst, tornadoes, and local cyclones; line faults caused by wind damage mainly include foreign body short-circuit and windage yaw $\operatorname{trip}^{[4,5]}$.

(1) Foreign body short-circuit

Foreign body short-circuits are mainly caused by advertising cloth, balloons, plastic films, bird repellent belts, kites and other long strip or sheet materials wound on the ground wire or pole tower, and the air gap is short-circuited, as shown in Figure 1. These foreign bodies are generally easy to cause line faults under windy weather conditions, and the randomness is relatively large.

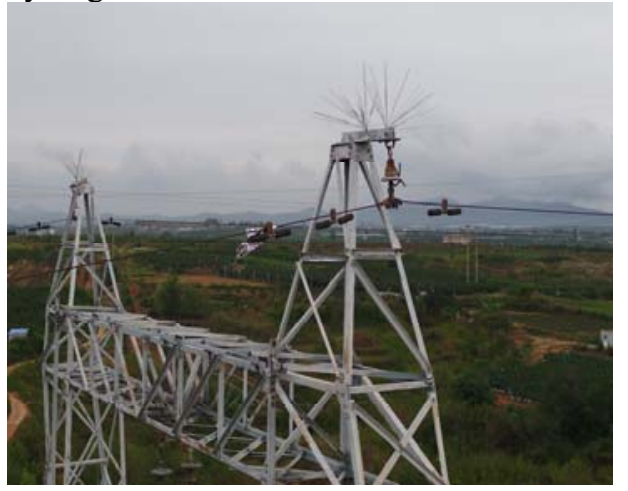

Fig.1. Bird repellent belt on overhead ground wire

(2)Windage yaw trip

Windage yaw trip is mainly caused by discharge tripping due to insufficient clearance distance after the wire deflects under the action of wind. It occurs under working voltage conditions, and the success rate of reclosing is low. Generally, strong winds that occur in local areas are the direct cause of line windage yaw tripping ${ }^{[5,6]}$.

\subsection{Fault data analysis}

In order to analyse the characteristics of wind-induced fault disasters in Shandong power network, this paper combines the wind-induced fault trip data of $220 \mathrm{kV}$ and above transmission lines from 2015 to 2019, and the overall situation of the trip is shown in Figure 2:

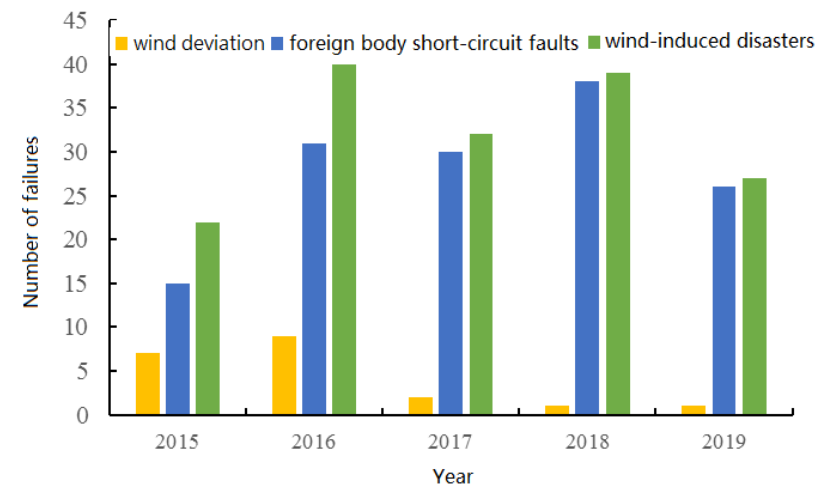

Fig.2. Statistics of wind-induced trips from 2015 to 2019

From Figure 2, it can be seen that the Shandong power network has an average of 32 wind-induced trips per year from 2015 to 2019, which is greatly affected by severe weather. Among them, the number of wind deviation trips in 2015 and 2016 were 7 and 9 respectively, far exceeding 2 in 2017, 1 in 2018 and 1 in 2019 . The main reason was that the overall $220 \mathrm{kV}$ windprone line was installed with wind protection. Measures such as partial fittings and jumper transformation can effectively reduce the occurrence of wind deviation accidents. At the same time, the probability of foreign body short-circuit faults in the past five years is far greater than the occurrence of wind-biased faults. Among them, as many as 40 and 39 in 2016 and 2018, it has seriously affected the safe and stable operation of the power network.

The statistics of wind-induced trips according to the months of trip occurrence are shown in Table 1: windage yaw trips are concentrated in June and July, mainly in summer when downburst is prone to occur. The shortcircuit of foreign body mainly occurs from March to August, mainly in spring and summer when downburst weather is prone to occur.

Tab.1 According to the monthly statistics

\begin{tabular}{|c|c|c|c|}
\hline Monthly & $\begin{array}{c}\text { Wind deviation } \\
\text { (times) }\end{array}$ & $\begin{array}{c}\text { Foreign body } \\
\text { short } \\
\text { circuit(times) }\end{array}$ & $\begin{array}{c}\text { Sum } \\
\text { (times) }\end{array}$ \\
\hline Jan. & 0 & 2 & 2 \\
\hline Feb. & 1 & 2 & 3 \\
\hline Mar. & 1 & 25 & 26 \\
\hline Apr. & 2 & 16 & 18 \\
\hline May. & 0 & 16 & 16 \\
\hline Jun. & 9 & 17 & 26 \\
\hline Jul. & 4 & 19 & 23 \\
\hline Aug. & 2 & 16 & 18 \\
\hline Sept. & 1 & 4 & 5 \\
\hline Oct. & 0 & 11 & 11 \\
\hline Nov. & 0 & 11 & 11 \\
\hline Dec. & 0 & 1 & 1 \\
\hline
\end{tabular}


According to the statistics of voltage level, foreign body short circuits mostly occur on $220 \mathrm{kV}$ lines, and the number of trips is as high as 130 times, accounting for $92.8 \%$ of the total number of foreign body short circuit trips; wind deflection tripping faults mostly occur on $500 \mathrm{kV}$ lines, with 13 trips, accounting for $65 \%$ of the total number of wind deflection trips.

It can be seen that foreign body short circuits account for $87.5 \%$ of the total wind-induced faults, mainly in spring and summer when strong squall line is prone to occur; wind deflection tripping mostly occurs on $500 \mathrm{kV}$ voltage level lines, and the success rate of reclosing is low, only $30 \%$. The fault mainly occurred in the summer when strong squall line occurred.

\section{Wind-induced failure model analysis}

Through the analysis of wind-induced fault data in the past five years, it can be known that foreign body shortcircuit faults occur frequently, which is the most important type of fault in wind-induced fault disasters. The occurrence of foreign body short-circuit faults is closely related to geographical location, meteorological conditions, hidden danger factors, etc. And winddeflection faults mainly occur in short-term severe convective weather. This paper combines the characteristics of the fault to establish wind deflection faults and foreign body short circuit models.

(1)Wind deviation warning

Through the analysis of the wind deviation trip mechanism, it can be known that the cause of the trip is insufficient clearance distance. According to the data analysis of wind deviation for 5 years, it can be seen that the wind level within a short period of time when the trip occurs is above 7, that is, the wind speed is greater than $13.8 \mathrm{~m} / \mathrm{s}$. As the wind speed increases, the wind deflection angle becomes larger, and the minimum air gap $d$ will be smaller than the minimum gap $D$ allowed by the regulations, and windage yaw flashover is prone to occur. Take the calculation of the minimum air gap of the middle phase jumping wire of the strain tower as an example, as shown in Figure 3 is a schematic diagram of the strain tower.

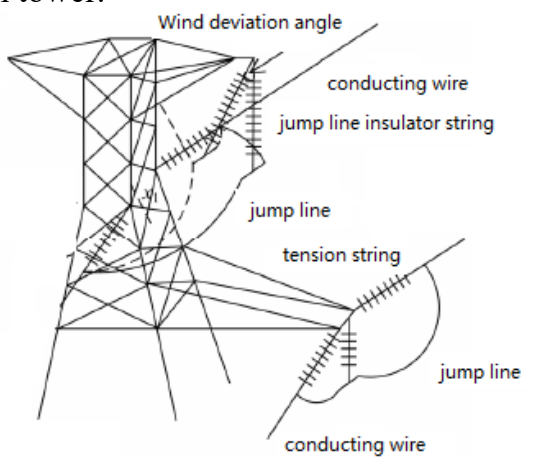

Fig.3. Schematic diagram of strain tower

The minimum gap $\mathrm{d}$ between the middle phase jumping wire and the tower body under wind deviation is calculated as follows:

$$
d=l \cdot \cos \phi \cdot \sin (k+\beta / 2)-a / 2
$$

$$
k=\arctan \frac{n-(m+a / 2) \cdot \sin \theta-l \cdot \cos \varphi \cdot \sin (\beta / 2)}{l \cdot \cos \varphi \cdot \cos (\beta / 2)+p / 2}
$$

formula:

$l$ — tension string length, $\mathrm{m}$;

$\varphi$ — tension string inclination, ${ }^{\circ}$;

$m$ _-jumper hanging string length, $\mathrm{m}$;

$n-$ cross arm length, $\mathrm{m}$;

$p$ - Section width of tower body at hanging

line of medium phase conductor.

the section width of the tower body where the intermediate phase conductor is hung, $\mathrm{m}$;

$a$ - jumper diameter, $\mathrm{m}$;

By comparing the calculated minimum air gap with the standard value, that is, whether the instantaneous maximum wind speed is greater than $13.8 \mathrm{~m} / \mathrm{s}$. It can be analyzed and judged whether it will cause the wind deviation trip, so as to realize the real-time calculation and early warning of the wind deviation trip fault.

(2)Visualized foreign body recognition

In recent years, the number of visual monitoring devices installed in Shandong Power Network has exceeded 35,000 sets, realizing real-time monitoring of the whole process in the channel named "three lines and two points" like UHV/cross-regional lines, mountainous lines, power lines, hidden danger points of external damage, and three-span click power lines .In order to realize early warning and real-time warning of foreign body short-circuit, This paper constructs an early warning analysis model of line wind-induced foreign body short-circuit faults that takes into account the integration of meteorological data and visualization. Based on the visual monitoring device, the line micrometeorological monitoring device and the meteorological data of the meteorological department, the hidden danger area classification method and the channel hidden danger distribution geographic map are established according to the importance of the line, geographical characteristics and the distribution map of the network wind area. Through the combination of realtime visual images in the channel and regional hidden danger information, analyze and determine whether there are suspected foreign bodies and types of foreign bodies in the wire, and provide real-time alarms. Combining meteorological information to integrate wind speed and the distribution map of hidden dangers in the area to achieve a three-level risk warning of wind-induced foreign body short circuit Combining the characteristics of the wind speed when the wind-induced foreign body short circuit fault occurred before, the wind speed is divided into three levels: clear wind $(3 \sim 8 \mathrm{~m} / \mathrm{s})$, high wind $(8 \sim 13.8 \mathrm{~m} / \mathrm{s})$ and strong wind (above $13.8 \mathrm{~m} / \mathrm{s})$.Among them, short circuit faults caused by kites, balloons, etc. frequently occur under clear wind conditions, short circuit faults caused by plastic films, billboards, etc. frequently occur in high wind weather, and short circuit faults caused by temporary construction facilities in strong wind weather. 
The geographical features of the foreign body short circuit include greenhouse area, garbage dump, temporary construction area and other four regional features. The wind area map is divided into 30-year, 50year and 100-year wind area map distribution levels. The hidden dangers of the passage include special attention hidden danger area, important hidden danger area and general hidden danger area.

\section{Wind-induced disaster early warning system analysis}

\section{(1) GIS platform}

In order to provide real-time warning and early warning of wind-induced disasters, this paper uses the construction of WebGIS as the background and uses the open source GeoServer to establish the basic platform of a GIS-based transmission line wind-induced disaster early warning system. The entire structure uses GeoServer to publish maps, and Openlayers uses maps. They provide services for the platform together.

GeoServer is an open source Java project of the OpenGIS Web server specification. Users can use GeoServer's convenient boundaries and release geographic data, and can share spatial geographic information conveniently and quickly. It supports Shapefile, PostGIS, VPF, MySQL, ArcSDE, Oracle, Maplnfo and other formats and hundreds of projections; at the same time, it can output network maps in gif, KML, png, jpeg, SVG and other formats.

Use the WMS and WFS services provided by GeoServer in the wind-induced disaster early warning system. The service for publishing map data is WMS service. WFS is equivalent to the query function in common desktop programs.It supports queries based on attribute field, queries based on spatial geometric relationship and joint queries of two combinations.

(2)Function module

The GIS-based early warning system for windinduced disasters on transmission lines mainly includes the following functions:

1)Homepage: display the distribution of the transmission lines under jurisdiction on the geographic information platform according to different voltage levels $(220 \mathrm{kV}$ and $500 \mathrm{kV}$, etc.).Display the distribution of the towers with different types of towers (straight towers, strain towers, etc.).And display the distribution of monitoring devices (micro-meteorological monitoring devices, video image monitoring devices).

2)Online monitoring: Display the real-time monitoring data of the micro-meteorological monitoring device, and provide a warning display for wind speeds exceeding $13.8 \mathrm{~m} / \mathrm{s}$;

3)Real-time warning: According to the visual image of the connected channel, if it is judged that there is a foreign body wire, then combine with the type of hidden danger area in the area of the line and the type of foreign body that may appear, confirm the suspected foreign body wire, and give real-time warning of the judgment result to the person in charge of the line through the dual mechanism of SMS and WeChat;
4)Wind disaster early warning: Provide the warning of wind deviation disasters based on the magnitude of the wind force and the calculated minimum air gap results;

5)Information decision: A large amount of historical fault data can be stored and collected, providing powerful information decision support for wind disaster status monitoring;

6)Radix saposhnikoviae daily: provide early warning of windy weather from combining micro-meteorological monitoring data and meteorological department data.

By constructing the core module of windinduced faults, this paper can visually and dynamically display real-time wind-induced disaster warnings and windy weather early warning information on the map, which can provide strong support for operation and maintenance staffs.

\section{Conclusion and discussion}

With the frequent occurrence of abnormally severe weather around the world, the wind disasters of power network caused by extreme weather have intensified, and wind-induced disasters have become an important factor threatening the safe operation of overhead transmission lines. This paper is designed for sudden wind disasters on transmission lines. It aims to establish a wind-induced disaster failure model based on geographic and meteorological characteristics and historical fault analysis, using micro-meteorological monitoring and real-time visual image data as the operating parameters of the early warning model, and provide real-time warning and early warning of windinduced disasters on the geographic information platform, which can effectively prevent the occurrence of major accidents. Thereby, this will greatly improve the lean and intelligent level of safety production management, and provide data support and a strong scientific basis for the realization of state maintenance of transmission lines. According to the research work of this paper, the following prevention suggestions are put forward against wind-induced disasters:

(1) Take measures such as installing heavy hammers for sections with small windage yaw angle to resist extremely severe windy weather. And install micro-meteorological online monitoring devices in micro-topography and micro-weather areas of important lines;

(2) Against plastic greenhouses, mulching films, shading nets, and reflective film dense areas, adequately do a good job of wire protection publicity, and avoid foreign bodies from hanging up the ground wire and tower body from the source;

(3) Strengthen special line patrols before and after severe weather such as strong winds, and remove foreign bodies as soon as they are found. 


\section{Acknowledgments}

This work was supported by the science and technology project of STATE GRID Shandong Electric Power Company under Grant 5206041801H3.

\section{References}

1. XU Wenjun, YANG Hongming, ZHAO Junhua, et al. Probability Calculation of Broken Transmission Lines and Collapsed Towers Under Ice Storms[J]. Automation of Electric Power Systems,2011,35( 1) : 13-17.

2. LIN zilun, GUO Lina,GUO Feiyan,et al. Analysis of atmospheric circulation patterns and influencing factors for summer precipitation anomaly in Shandong Peninsula [J].Journal of Marine Meteorology,2019,39(01):55-67.

3. GAO Xiaomei, JIANG Jing, LIU Chang,et al. Frequency variation characteristics of typhoons affecting Shandong in recent 67 years and their relationship with several climate factors. Journal of the Meteorological Sciences, 2018, 38( 6) : 749-758.

4. BIAN Rong,XU Qing,YU Enke,HUANG Mingfeng,LOU Wenjuan,HU Wenkan,ZHANG Ligang. Multi-variate state monitoring and wind bias reliability analysis of a transmission towerline system under action of typhoon[J]. JOURNAL OF VIBRATION AND SHOCK, 2020, 39(03):52-59.

5. HOU Hui,YU Jufang, HUANG Yong,WANG Hongbin, YU Shiwen, GENG Hao.Risk Assessment of Transmission Line Trip Caused by Windage Yaw Under Typhoon[J].High Voltage Engineering,2019,45(12):3907-3915.

6. ZHU Ye,WANG Haitao,WU Nian,et al. Icing Online Monitoring Dynamic Prediction Model[J]. High Voltage Engineering,2014,40(05) :13741381.

7. ZHAO Ruiqin. Damage Assessment of Transmission Line Fire Disaster Based on Lidar[J]. Journal of Catastrophology, 2019,34 (2):52-56.

8. Guo Tao, Liu Rui, Shen Ping, et al. A Disaster Prevention and Reduction Analysis System in Transmission Line Based on Power Big Data---A Case Study on Guizhou Power Grid[J]. Journal of Catastrophology, 2016, 31(01):135-138. 